\title{
Governança Participativa: possibilidades e desafios na gestão local
}

\author{
Participative Governance: possibilities and challenges in local management
}

\section{Gouvernance Participative: possibilités et défis dans la gestion locale}

\author{
Gobernanza Participativa: posibilidades y desafios en la gestión local
}

\author{
Tainá Rodrigues Gomide Souza Pinto ${ }^{1}$ \\ Simone Martins ${ }^{1}$ \\ Danielle Silveira Leonel ${ }^{1}$ \\ Ivan Beck Ckagnazaroff ${ }^{2}$
}

Recebido em 05/10/2017; revisado e aprovado em 29/11/2017; aceito em 20/12/2017

DOI: http://dx.doi.org/10.20435/inter.v19i3.1730

\begin{abstract}
Resumo: Este trabalho busca compreender como a participação social se configura em arranjos de governança estabelecidos pelo governo do município de Viçosa e também os desafios do governo local na adoção de uma governança participativa. O estudo possui abordagem qualitativa, tendo a entrevista como a principal técnica para a coleta de dados. Conclui-se que o governo local analisado não possui uma governança participativa instituída e, dentre os desafios, a falta de autonomia financeira e de evidências de uma sociedade ativa.
\end{abstract}

Palavras-chave: Governança Participativa; gestão local; participação.

\begin{abstract}
This paper seeks to understand how social participation is configured in governance arrangements established by the municipality of Viçosa and also the challenges of local government in adopting participatory governance. The study has a qualitative approach, with interviewing as the main technique for collecting data. It is concluded that the local government analyzed does not have participatory governance instituted. Keywords: Participative Governance; local management; participation.

Résumé: Cet article cherche à comprendre comment la participation sociale est configurée dans les dispositifs de gouvernance mis en place par la municipalité de Viçosa et aussi les défis de gouvernement local dans l'adoption de la gouvernance participative. L'étude a une approche qualitative, l'interview étant la principale technique de collecte des données. Il est conclu que le gouvernement local analysé n’a pas de gouvernance participative établie.
\end{abstract}

Mots-clés: Gouvernance Participative; gestion locale; participation.

Resumem: Este trabajo busca comprender cómo la participación social se configura en arreglos de gobernanza establecidos por el gobierno del municipio de Viçosa y también los desafíos de lo gobierno local en la adopción de una gobernanza participativa. El estudio tiene un enfoque cualitativo, teniendo la entrevista como la principal técnica para la recolección de datos. Se concluye que el gobierno local analizado no posee una gobernanza participativa instituida.

Palabras clave: Gobernanza Participativa; gestión local; participación.

\section{INTRODUÇÃO}

Com o processo de redemocratização e posteriormente com as propostas de reforma do Estado brasileiro (meados dos anos 1990), novas formas de atuação do Estado e de pensar as políticas públicas começam a emergir. Dentre as novas diretrizes para a gestão pública, pode-se destacar a busca pela legitimidade da ação estatal, pela conexão entre administração pública e o contexto político, por equilíbrio entre a eficiência econômica e a participação política.

A criação de organismos de participação popular nas políticas públicas foi um meio encontrado para melhorar a qualidade dos serviços e das políticas públicas e permitir que representações

\footnotetext{
${ }^{1}$ Universidade Federal de Viçosa (UFV), Viçosa, Minas Gerais, Brasil.

2 Universidade Federal de Minas Gerais (UFMG), Belo Horizonte, Minas Gerais, Brasil.
} 
sociais tivessem acesso ao governo, dando início ao processo de maior interação entre o governo e as representações sociais, compartilhando a responsabilidade por tomadas de decisões sobre alguns problemas públicos.

Essas transformações seguem a tendência de governança democrática que contempla a permanente avaliação da cidadania. Com as mudanças, era esperado mais eficiência na gestão pública e decisões coletivas legítimas, ou seja, o que se buscava era recuperar a vitalidade democrática e melhorar o funcionamento da Administração Pública.

Entretanto, na literatura voltada para compreender a efetividade das instituições participativas, o que se nota é que as experiências ditas ou consideradas ou com pretensão de governança democrática sofrem percalços ao longo do seu funcionamento. Por um lado, são destacados problemas oriundos das Instituições participativas criados após a Constituição Federal de 1988, que dizem respeito a sua composição (ARAÚJO, 2007), a sua atuação uma vez que não espelham as matizes da sociedade civil, a falta de clareza com relação ao papel que deve ser por elas exercidas, conforme Sampaio e Farah (2006), Martins (2015). São problemas que dizem respeito principalmente ao desempenho das instituições participativas. Além disso, é identificado que essas instituições têm contribuído de forma modesta para a incorporação de novos atores da sociedade civil nos arranjos de governança e nos processos políticos (CARVALHO, 1995; ANDRADE, 1998; CARNEIRO, 2002; COELHO; NOBRE, 2004; AVRITZER, 2008; OLIVEIRA, 2009; PIRES, 2011; MARTINS; CKAGNAZAROFF; LAGE, 2012).

Considerando o importante papel que deveria ser desempenhado pelas instituições participativas nos processos de governança públicos, o presente estudo analisa o caso do município de Viçosa, MG, sendo propostas as seguintes questões de pesquisa: Como se configura a participação social em arranjos de governança estabelecidos em Viçosa, MG? Quais os desafios enfrentados pela administração pública de Viçosa na adoção de uma governança participativa?

Acredita-se que o trabalho ganha importância pela possibilidade de contemplar as temáticas de governança democrática, priorizando o olhar dos gestores e dos funcionários públicos, de maneira a permitir elucidar as possibilidades e desafios das formas de aproximação instituídas/ vislumbradas entre o governo e a sociedade, que, por sua vez, pode apresentar questões para futuras investigações.

\section{MARCO TEÓRICO}

As seções seguir tratarão da governança participativa que fornecerá as dimensões que permitem analisar o caso de Viçosa, MG, segundo o recorte proposto.

\subsection{Governança Participativa}

O conceito de governança, embora se origine do mundo das empresas, como afirma Dallabrida e Becker (2003), tem sido bastante discutido ao longo dos últimos anos no âmbito da gestão pública. Segundo Bevir (2011a), a adoção da governança na administração pública põe em relevo a noção de redes como arranjo de governança. A ideia de rede é vista como uma alternativa ao modelo burocrático de administração na medida em que busca envolver diferentes atores interessados em determinada questão em processos caracterizados pela influência mútua, complementariedade de recursos e coordenação mais horizontal. 
São notados na literatura esforços com bases ideológicas distintas que culminam em propostas de modelos de governança gerencial e democrático-participativo. No que se refere ao modelo gerencial, a ênfase recai na eficiência e eficácia. A tecnocracia ganha destaque, assim como a centralidade nas decisões governamentais (BECK, 2009). Em se tratando do modelo democrático-participativo, o destaque está na mudança de relação entre a sociedade e o governo e na inserção da sociedade nas decisões políticas (PETERS, 2005; BECK, 2009).

Considerando o objetivo do presente estudo de compreender como a participação social se configura em arranjos de governança estabelecidos pelo governo municipal de Viçosa, MG, e também os desafios da administração pública local na adoção de uma governança participativa, optou-se por pautar a discussão sobre o modelo de governança democrático-participativo.

Ao analisar as produções acadêmicas que abordaram a temática "Governança no setor público" nos últimos 20 anos, embora com diferentes ênfases e inúmeras nomenclaturas (governança pública, governança em rede, rede de governança, governança democrática, boa governança, dentre outras) nota-se uma atenção voltada para as mudanças de paradigmas, de uma racionalidade burocrática para democrática (PETERS, 2005; BRUGUÉ, 2011; SPEER, 2012), de Estado gestor (hierárquico, burocrático, controlador), para o Estado cooperativo (que atua em conjunto com uma rede de parceiros ou colaboradores) (MAYNTZ, 2000; KISLLER; HEIDEMANN, 2006 ; BEVIR, 2011a; PIRES , 2015); de uma sociedade consumidora de políticas públicas para protagonista na construção de projetos coletivos (MAYNTZ, 2000; PETERS, 2005; SCHNEIDER, 2005; MILANI, 2008; BRUGUÉ, 2011).

Com modelos de governança participativa, espera-se que a autoridade do governo seja movida pelo interesse público, assim, demanda do fortalecimento da cidadania. O que se espera com a democratização dos espaços de poder é a melhoria decisória, por meio da incorporação ao processo político do conhecimento local, ou seja, conhecimento/experiência de atores locais, suas demandas e conflitos. Assim, os governos mais abertos são compreendidos como meios para promover valores democráticos (SPEER, 2012), alimentando o sonho de transformar sujeito em cidadão (OFFE, 2001). Outro argumento chave é a possibilidade de gerar accountability (SPEER, 2012) - seja Accountability viabilizada com controles internos e externos para minimizar o comportamento oportunista dos burocratas ou accountability pensada para incluir a sociedade como principal agente e controlador do governo, fiscal de seus próprios interesses. Ou seja, maior participação da sociedade nas deliberações sobre problemas coletivos e o exercício do controle da sociedade sobre o governo como possibilidades de contribuir para aumentar a capacidade de resposta dos governos e o melhorar o fluxo de informações dos cidadãos em direção ao governo.

De forma geral, o que se busca com a governança democrática é fortalecer o governo para que os objetivos sejam alcançados, tornar a gestão mais eficiente e restabelecer a confiança no setor público, recuperar a vitalidade democrática e garantir a legitimidade política, para que se tenha governabilidade (DINIZ, 1996; PETERS, 2005; FREY, 2007; OLIVEIRA, 2009; BECK, 2009).

Em se tratando das motivações para as proposições de arranjos de governança participativa, destaques para as falhas observadas nos sistemas convencionais de responsabilização governamental (SPEER, 2012), para a crise da democracia representativa e de legitimidade (DINIZ, 1996; SUBIRATS, 2001; CASTELLS, 2001; PETERS, 2005; MILANI, 2008, BEVIR, 2010a; LA FUENT, 2010 ); para a onda de reformas e de descentralização observadas no mundo inteiro, como alternativas ao modelo centralizado e rígido de governo (DINIZ, 1999; CASTELLS, 2001), 
para a mudança de paradigma de uma racionalidade tecnocrática para a deliberativa, retirando do governo a exclusidade para se discutir e decidir sobre as políticas públicas (SCHNEIDER, 2005; PETERS, 2005; BEVIR, 2011; BRUGUÉ, 2011).

Leva-se em conta, na adoção do modelo de governança participativa, o envolvimento dos afetados pelas políticas nos processos decisórios e de controle, compreendendo essa interação entre Estado e sociedade como um bom caminho para o governo responder de maneira mais eficiente às demandas dos cidadãos. Ou seja, a governança surge com diferentes visões, mas em seu centro se encontra o processo público, contemplando o permanente exercício da cidadania para democratizar a administração pública.

Speer (2012), a partir de uma revisão de literatura, avalia o potencial da governança participativa. Embora aponte benefícios que se referem ao aumento da responsabilidade dos governos, a melhoria nos serviços e, consequentemente, contribuição para o bem-estar, destaca inúmeros desafios. Desafios estes relacionados principalmente à escassez de dados que permitam melhor conhecer os efeitos da governança participativa, o seu impacto sobre a capacidade de resposta do governo e para o aprofundamento na democracia.

Nas discussões sobre os benefícios da governança participativa, a democratização dos processos políticos e administrativos, a responsabilização e a eficiência dos governos e a necessidade de restabelecer a confiança no setor público estiveram e continuam em pauta (PETERS, 2005; BEVIR, 2011b; SPEER, 2012). Aumentar a eficiência do poder público com um governo mais horizontal e contando com servidores mais motivados, pareciam alternativas para aumentar o grau de confiança e de cooperação e para incrementar a legitimidade (PETERS, 2005). Segundo Pires e Gomide (2015 ), há um redirecionamento dos arranjos centrais que se apoiavam em estruturas hierárquicas do Estado para arranjos com maior participação de diversos atores e dotados de mecanismos de coordenação.

De maneira geral, os estudos tendem a assumir uma forma mais participativa de democracia quando a associam a governança, introduzindo o debate e o diálogo nos processos de decisão. Trata-se de reforçar as formas de decisão deliberativas para que se obtenham resultados melhores e mais equitativos, com processos políticos transparentes e mais justos (BEVIR, 2010a; SPEER, 2012).

Assim, Peters (2005, p. 586) defende que, baseando-se tanto nos princípios democráticos quanto nas noções administrativas e de eficiência, a lógica presente na governança é "que a maior participação cidadã trará consigo maior qualidade na tarefa de governar". E, ainda, aumentará a confiança dos cidadãos. Participação esta que está contida na lógica de descentralização democrática, como formas de gestão inclusivas.

No que se refere à descentralização democrática no Brasil, esta é orientada e impulsionada por uma Constituição Cidadã (Constituição Federal de 1988) (BRASIL, 2000), que reconhece o município como ente federado e, portanto, propõe inovação na forma de governar. Além do otimismo, em termos de melhorar as respostas às demandas da sociedade plural considerando a proximidade com os cidadãos, também é destacado por Peters (2005) o incremento de legitimidade. Como já observado por Castells (2001), ao sinalizar os rumos dos Estados na era da informação, os governos locais e regionais foram idealizados como de maior potencial para se flexibilizarem diante das demandas da coletividade e para negociar com os seus cidadãos.

O processo de descentralização, que no Brasil esteve associado às reformas no setor público e à democratização, tira do governo federal o monopólio sobre o processo de formulação, 
implementação e avaliação das políticas públicas, voltadas para áreas sociais diversas, uma vez que os governos sub-nacionais passam a gozar de autonomia financeira, administrativa e política, havendo, assim, uma difusão de poderes (BECK, 2009). A hierarquia e os controles centralizados deram lugar a princípios como de flexibilidade, coordenação, participação cidadã e transparência administrativa para fazer frente à complexidade de relações que passam a se estabelecer entre o global, nacional, regional e o local (CASTELLS, 2001; BECK, 2009).

Nesse sentido, pensar o governo municipal por meio de arranjos de governança participativa passa a oferecer aberturas para o cidadão ativo exercer poder e influência dentro de um sistema pluralista para a elaboração de estratégias coletivas e prestação de serviços públicos (DINIZ, 1996; KEARNS, 1995; BEVIR, 2011b). Entretanto a descentralização formatada constitucionalmente demanda capacidade burocrática, demanda recursos para responder às demandas da coletividade. Assim, se apresentou o desafio para o governo municipal de lidar com um número maior de atores e com as complexidades referentes à articulação, à participação dos cidadãos na tomada de decisão das políticas públicas no local.

O desafio está em encontrar um equilíbrio entre preceitos ideológicos antagônicos, mas não excludentes (MAYNTZ, 2000), como, por exemplo, o equilíbrio entre a eficiência e a participação social, para não incorrer em paralisia decisória e em exclusão social; em contar com uma população ativa que pode ser mobilizada e incentivada a participar das ações do setor público (PETERS, 2005), e em ativar e coordenar atores sociais de tal maneira que intervenções públicas, da sociedade civil e "das organizações privadas, respondam às necessidades decorrentes do esforço de tratar adequadamente os problemas e fazer uso das oportunidades presentes na sociedade contemporânea" (BECK, 2009, p. 27).

Kearns (1995), por exemplo, faz uma ressalva em relação à participação dos cidadãos, que merece uma reflexão. $\mathrm{O}$ autor acredita que os cidadãos ativos têm tendência elitista, uma vez que, normalmente, são os especialistas e cidadãos da classe média alta que exercem a participação, e, consequentemente, o controle dentro da gestão pública. Muitas das vezes, esses cidadãos que fazem parte de uma elite são nomeados pelo governo ou chamados a participar por força da regulamentação legal. O autor aponta que essa participação elitista pode levar a uma forma paternalista de gestão pública local. Neshkova (2014) também discute a questão, indicando que normalmente os grupos de interesses ocupam espaços de discussão pública e que, geralmente, os cidadãos mais ativos muitas das vezes representam interesses privados que podem ser diferentes do interesse público em geral.

A opção pela flexibilidade da gestão para incorporar mecanismos de inclusão social nos seus processos políticos e administrativos impõe à gestão pública local a necessidade de instituir formas de coordenação da interação público-privada, principalmente em relação ao papel das redes de políticas.

Para Peters (2005), a governança é um modelo de condução mais democrática do Estado e da sociedade, uma nova forma de governar que impõe mudanças ao setor público, marcada pelo incremento da cidadania para qualificar a gestão, podendo contribuir para proporcionar a adaptação dos objetivos gerais de uma política aos contextos locais (SABEL, 2004). Como alternativa para melhorar o desenvolvimento, para solucionar problemas de captura da elite e formação de políticas clientelistas (SPEER, 2012), diversos mecanismos de participação social foram formatados a partir da Constituição Federal de 1988, tais como Fóruns, Audiências Públicas, Conselhos de Políticas Públicas, Ouvidorias, dentre outros. 
Arranjos de governança participativa são complexos e, portanto, desafiadores, mas que, segundo Pires e Gomide (2015, p. 203), "podem oferecer oportunidade para que uma pluralidade de atores usem seus conhecimentos, criatividade e recursos para a busca de formas novas e melhores de se produzir políticas públicas".

\section{PROCEDIMENTOS METOdOLÓGICOS}

Nesta seção, apresentam-se procedimentos, técnicas e métodos a serem utilizados no processo de realização da pesquisa, que é norteada pela abordagem qualitativa. Esse tipo de pesquisa costuma ser direcionada ao longo do seu desenvolvimento. Não busca enumerar dados, e sim descrevê-los e explicá-los mediante o contato do pesquisador com o objeto da pesquisa (VIEIRA; ZOUAIN, 2005).

Com a pesquisa, busca-se compreender como se configura o arranjo de governança estabelecido pelo governo do município de Viçosa, MG, e apresentar os desafios da administração pública local na adoção de uma governança participativa.

Para atingir tal objetivo, optou-se por estudar o município de Viçosa, MG, situado no interior de Minas Gerais, escolhido de maneira intencional, considerando a facilidade de acesso aos dados. O município conta com uma população de 77.000 mil habitantes, sendo esta predominantemente urbana (92\%) (INSTITUTO BRASILEIRO DE GEOGRAFIA E ESTATÍSTICA [IBGE], 2016). Vale destacar que o município possui tradição educadora, contando com faculdades privadas e uma universidade federal, sendo cerca de $50 \%$ da população estudantes (IBGE, 2016). Dessa forma, acredita-se nas possibilidades de geração de capital social no local e uma maior pressão por instituições de formas mais participativas de gestão, o que torna o município um caso interessante a ser estudado.

Os dados coletados na presente pesquisa foram obtidos por intermédio dos documentos referentes à gestão local, tais como site oficial, leis, decretos, atas entre outros; e por meio de entrevistas em profundidade, com atores protagonistas na gestão local, que configuram o universo de secretários de governo, totalizando 8 entrevistados. As entrevistas foram realizadas nos meses de março a abril de 2017 e posteriormente transcritas.

Para a análise e a apresentação dos resultados de pesquisa, foi utilizada a técnica análise de conteúdo, como método para interpretar o conteúdo de um texto. A análise de conteúdo, além de realizar a interpretação após a coleta dos dados, desenvolve-se por meio de técnicas de categorização (FLICK, 2009). Compreende três etapas: 1) pré-análise: seleção do material e a definição dos procedimentos a serem seguidos; 2) exploração do material: implementação dos procedimentos definidos; 3 ) tratamento dos dados e interpretação: geração de inferências e dos resultados da investigação, em que as suposições poderão ser confirmadas ou não (BARDIN, 1997). Optou-se por trabalhar com dimensões de análise previamente definidas a partir da literatura e levando em conta o objetivo da pesquisa, sendo: Percepção do Gestor sobre Participação Social e Arranjo de Governança. As categorias referentes ao Arranjo de Governança foram definidas a partir da revisão de literatura, considerando-as como essenciais para uma administração pública transparente e acercada da cidadania, fundamental para se pensar em arranjos de governança participativa. 


\section{ANÁLISE DOS DADOS}

Para melhor entendimento sobre o arranjo de governança instituído na cidade de Viçosa, MG, e como ele é permeável à participação social, as informações foram agrupadas em duas dimensões, sendo: Percepção do Gestor sobre Participação Social e Arranjo de Governança. Para a análise da dimensão Arranjo de Governança, foram contempladas categorias definidas a partir da leitura, sendo: Autonomia, Articulação, Processo de Decisão, Planejamento, Transparência e Prestação de Contas.

\subsection{Percepção sobre Participação Social}

Com a dimensão 'Participação Social', buscou-se compreender como os gestores públicos percebem a participação da sociedade na gestão pública local. Parte-se do pressuposto de que participar da gestão dos interesses da sociedade é participar da edificação da esfera pública, é consolidar novos espaços de poder (TELLES, 1994).

Os secretários entrevistados entendem que a participação social é incorporada na gestão municipal, pois, durante o funcionamento dos setores públicos (secretarias), "as portas ficam sempre abertas", e argumentam que todo cidadão que chega é bem atendido e tem retorno sobre a solicitação realizada. Nas falas, em nenhum momento, a sociedade foi referenciada como protagonista nos processos políticos e administrativos. Constatações de que a administração pública permanece voltada para dentro e que os gestores públicos não assimilam a participação social na perspectiva de incremento da cidadania para se pensar o local, para a construção de projetos coletivos, como uma alternativa para inovar na tarefa de governar.

Os secretários municipais entendem a gestão participativa como sendo aquela em que a decisão, embora centralizada, é compartilhada entre os secretários e os burocratas. Nas colocações dos entrevistados foi ignorado o potencial dos cidadãos em contribuir com sugestões ou críticas sobre os serviços públicos que recebem, o que vai de encontro com as perspectivas da descentralização democrática, em que, segundo Castells (2001) e Beck (2009), a maior aproximação com o cidadão é priorizada para fazer frente às complexidades e aos desafios impostos ao governo local para melhorar os resultados na oferta de bens e serviços públicos.

Foi observada a falta de afinidade dos gestores com os conceitos de governança participativa. No que se refere ao arranjo de governança nas diversas políticas públicas, observou-se que a participação social é pouco referenciada e, embora existam diversos conselhos de políticas públicas na cidade, as suas deliberações não foram consideradas nas falas dos entrevistados.

Ao serem questionados sobre a possibilidade de instituir um arranjo de governança participativa, de maneira geral, os secretários municipais apresentaram dificuldades, destacando: a falta de estrutura física, de recursos humanos e de recursos financeiros. Segundo eles, os servidores públicos e a sociedade não estão preparados para colocar em prática, e de forma efetiva, uma proposta de gestão participativa. No que se refere à sociedade, complementaram dizendo que a falta de preparo dos cidadãos ocorre por estes não conhecerem e não compreenderem as atividades e os processos desempenhados pela gestão pública; por não acreditarem nas ações do poder público, estando os cidadãos frustrados e sem esperança, uma vez que, devido à falta de recursos, grande parte de suas demandas não são atendidas. Relataram, ainda, que na maioria das vezes o cidadão demanda questões de interesses individuais, sendo poucas as demandas que contemplam o interesse coletivo. 
Tais respostas repetem o senso comum, em certa extensão, da falta de competência política e técnica por parte dos cidadãos para se envolver na coisa pública, expressa o reconhecimento por parte da burocracia pública da frustação do cidadão em relação à falta de capacidade de resolução de problemas por parte da prefeitura, ou seja, o reconhecimento da falta de efetividade.

\subsection{Arranjo de Governança}

Antes de buscar compreender o modelo de governança pública instituído, buscou-se primeiramente, entender a gestão a partir de uma livre definição por parte dos entrevistados, propondo uma discussão sobre o tipo de gestão e o papel por ela desempenhado.

Pode-se verificar, a partir das entrevistas, que a maioria dos gestores públicos acredita realizar uma gestão 'aberta', considerando que os funcionários têm acesso ao gestor. Trata-se de algo valorizado por eles por possibilitar que os servidores públicos tomem conhecimento de todas as ações da gestão e se envolvam nos processos de tomadas de decisão.

A percepção apresentada é compartilhada por quase todos os entrevistados (90\%), com exceção dos que atuam na secretaria de finanças e fazenda que consideram a gestão como sendo hierarquizada e muito burocratizada, sendo esse modelo de gestão, na visão deles, necessário considerando o objeto do setor. A despeito das considerações dos secretários de finanças e da fazenda, a maioria dos entrevistados define a gestão como participativa, sendo aquela que estabelece um canal de comunicação e toma decisões envolvendo os funcionários da própria burocracia.

De forma complementar, os entrevistados admitem que não foram preparados para o cargo assumido e que a gestão (participativa ou hierarquizada e burocratizada) é baseada em ações, e não em planejamento, ainda que compreendam o planejamento como necessário.

O que se pode notar é que, na concepção de governança apresentada pelos secretários de governo entrevistados, a participação social não é tratada. Não foi identificada preocupação, ou até mesmo intenção, em adotar um modelo de gestão que envolva a sociedade, que priorize a inserção social nas discussões ou implementações das políticas públicas.

Para melhor compreender o arranjo de governança instituído, foram propostas categorias para discussão, consideradas importantes para os arranjos de governança participativa, tais como: autonomia, articulação, tomada de decisão, planejamento, transparência e prestação de contas, como segue.

\subsection{Autonomia}

Com a categoria de análise 'Autonomia', busca-se contemplar a compreensão dos gestores sobre a autonomia administrativa, financeira e política do órgão público local estudado, o que, de acordo com os princípios da descentralização, deveria se traduzir em uma difusão de poderes, no fortalecimento do governo local (BECK, 2009).

Os entrevistados asseguram que possuem autonomia administrativa, associando-as com a liberdade para gerenciar as secretarias que comandam, para planejar as ações e para tomar decisões. Entretanto a maioria relatou que essa autonomia acaba sendo relativa, devido à restrição financeira. Os entrevistados enfatizaram que conhecem a situação orçamentária do município e que compreendem a dificuldade do governo local para atender as necessidades específicas de cada secretaria. 
A restrição financeira ressaltada pelos entrevistados é atribuída ao governo local como um todo, e não somente em relação à secretária a qual se encontra vinculado. Eles compreendem a situação como desafiadora, devido ao grau de dependência do município aos repasses do governo federal e estadual, o que, consequentemente, resulta em restrição orçamentária, justificando a escassez de recursos humanos como já relatado.

Além disso, segundo os entrevistados, parte significativa dos recursos repassados pelo Estado ou União consta no orçamento como recursos vinculados, deixando pouca margem para atender as demandas das secretarias e da cidade. De tal maneira, a falta de recursos financeiros, a dependência dos repasses governamentais e o engessamento do orçamento impõem restrições para o exercício da autonomia política. Ou seja, a falta de autonomia tem sido considerada como um limitador para inovações na tarefa de governar e para romper com uma lógica de governança hierarquizada e burocratizada.

\subsection{Articulação}

Com a proposição da categoria de análise 'Articulação', buscou-se compreender a maneira como as relações são mantidas e articuladas pelo poder executivo, considerando que a adoção de um modelo de governança participativa implica lidar com diferentes atores e instituir a coordenação de processos de forma mais horizontal, pois são caracterizados pela influência mútua (BEVIR, 2011b).

De tal forma, buscou-se compreender como são realizadas as articulações entre as secretarias municipais, entre o poder executivo com outros atores do poder legislativo, de instituições não governamentais e sociedade civil organizada.

Internamente, a interação entre as secretarias do município ocorre de forma satisfatória. Segundo os secretários, essa interação é atribuída ao fato de existir uma secretaria de governo (Superintendência de Governo), hierarquicamente superior às demais, que desempenha o papel de estimular a interação entre todas as secretarias do município e garantir que a articulação entre elas ocorra quando tiverem objetivos e projetos em comum.

Entretanto, segundo os secretários, essa interação observada entre as secretarias não ocorre com os demais entes federativos e com o legislativo. Os entrevistados relataram que as articulações mais frequentes são entre as superintendências regionais e as secretarias de governo, para repasse de diretrizes para a execução das ações. Assim, admitem que as secretarias locais atuam de forma a executar o que foi direcionado pela superintendência, e não de forma propositiva.

O governo estadual e federal aparece como ator político importante nas articulações com o chefe do governo local. De acordo com os entrevistados, trata-se de interação para questões de política, que pode ser um facilitador quando há coincidência de cor partidária ou implicando dificuldades quando se deparam com a situação oposta.

Para os entrevistados, a interação com o poder legislativo local é pequena, sendo realizada a partir de comunicados e solicitações oficiais, ou para prestar algum tipo de esclarecimentos. Foi possível identificar um distanciamento por parte da câmara de vereadores em relação às atividades das secretarias locais. Mesmo quando o assunto é prestação de contas, tema obrigatório que aproxima os diferentes grupos de políticos e executivos, não há aproximação ou articulação entre eles. Nessa relação entre as secretarias locais e o poder legislativo, também é possível perceber influência da questão político-partidária, uma vez que os secretários relataram que os vereadores de oposição é que interagem um pouco, ao cobrar determinados serviços, 
sendo essas cobranças, na maioria das vezes, relacionadas a algum pedido individual, e não representando a comunidade como um todo.

O setor privado também emergiu como ator com o qual as secretarias interagem, mas de forma esporádica. Quando ocorrem, o intuito é de estabelecer parcerias para o desenvolvimento local.

O que se observa na categoria 'Articulações' é que a gestão local não adotou uma forma de governança cooperativa, que atue em conjunto com uma rede de parceiros ou colaboradores, conforme as definições de Mayntz (2000), Kisller e Heidemann (2006), Bevir (2011b), Pires e Gomide (2015).

\subsection{Tomada de decisão}

Com a categoria de análise 'Tomada de decisões', buscou-se compreender como se dá o processo de decisão nas secretarias e na administração pública local, identificando os atores que participam desse processo. Essa categoria foi proposta considerando a importância do diálogo e do debate envolvendo o maior número de atores nas decisões governamentais para o alcance de melhores resultados, para que se tenham processos de gestão mais transparentes e decisões mais justas (BEVIR, 2010a; SPEER, 2012).

O processo de tomada de decisão relatado pela maioria dos secretários é realizado da seguinte forma: os funcionários e, principalmente, os chefes de sessões que possuem ligação com a questão a ser decidida são ouvidos, fornecem dados e opiniões, porém quem toma a decisão é o secretário. Dessa forma, percebe-se que a decisão não é realizada de forma colegiada, uma vez que não ocorre a discussão com todos os chefes de sessões e demais funcionários das secretárias, a discussão é realizada somente com os funcionários que estão envolvidos diretamente com a questão a ser decidida.

Além dos funcionários das secretarias ligados à questão a ser decidida, alguns atores governamentais influenciam no processo de tomada de decisão de todas as secretarias estudadas, sendo eles a procuradoria jurídica da prefeitura e o superintendente de gestão pública. Este último, quando há questão política a ser decidida.

Outros atores não governamentais foram referenciados pelos entrevistados, tais como os conselhos específicos de cada área, os sindicatos dos professores - no caso específico da secretária de educação, e o ministério público - no caso da secretária de saúde.

Embora os conselhos tenham sido citados, não foram associados a uma participação efetiva na tomada de decisão, uma vez que os secretários consideraram que a atuação deles é protocolar, não atuando de forma propositiva.

Assim como na categoria 'Articulações', notou-se que os processos decisórios sinalizam para uma gestão local fechada, distante da cidadania, no qual não são observadas inovações ou características de uma governança participativa.

\subsection{Planejamento}

Considerando que o 'planejamento' passa por decisões políticas que contemplam a participação social, em se tratando de modelos de governança democrática, se apresenta como importante categoria de análise. O planejamento realizado numa perspectiva de governo mais horizontal, com a inclusão de diferentes atores, pode ser um meio para a democratização dos 
processos políticos e administrativos, o que, segundo Peters (2005), pode contribuir para aumentar o grau de confiança e de cooperação e para incrementar a legitimidade.

A partir das entrevistas realizadas com os secretários municipais, identificou-se que o planejamento municipal ocorre seguindo uma lógica estabelecida pelo gabinete do prefeito junto com o superintendente de gestão pública do município. Primeiramente, a superintendência de gestão pública determina as diretrizes e prioridades que cada secretaria deve seguir. A partir dessas orientações, os secretários devem se organizar para cumpri-las. As secretarias apresentam, então, ao superintendente de governo, o plano de metas (com as prioridades e a definição das metas) e os relatórios de ações quadrimestralmente. Além dessa apresentação de relatórios quadrimestrais, as secretarias são convocadas mensalmente pelo superintendente para uma reunião na qual todos os secretários relatam as ações desempenhas pela sua secretaria, visando a maior integração entre as secretarias do município.

Segundo o superintendente, esse formato de planejamento (implementado em 2015), foi criado para coordenar as atuações das secretarias municipais, o que não era feito anteriormente, deixando as secretarias sem direcionamento. O superintendente apresentou relatos sobre o programa Gestão por Desenvolvimento, com o qual objetivou implementar um formato gerencial para as ações da gestão local, que foi proposto após estudos e reflexões e representa um avanço em termos gerenciais.

Todas as informações recebidas sinalizam para a ausência de participação cidadã no processo de planejamento. Embora reconhecida relevância de contemplar os diferentes escalões de uma prefeitura no processo de planejamento, este se realizada com o distanciamento da cidadania, contrariando as expectativas de mudanças de paradigmas, de uma racionalidade burocrática para democrática (PETERS, 2005; BRUGUÉ, 2011).

\subsection{Transparência e prestação de contas}

O cerne da governança democrática está no processo público, na proposta de administração aberta e transparente, nas possibilidades de interação entre o Estado e a sociedade. De tal forma, tratar a transparência pública e prestação de contas se tornou essencial. Como afirma Ruediger (2003, p. 1279), a transparência é "o eixo vertebral de possibilidades de reestruturação do Estado em que a dimensão republicana e democrática retome sua centralidade política".

Assim, buscou-se compreender a partir da percepção dos entrevistados como ocorre a difusão das ações, de informações, como é estabelecida a comunicação entre os atores governamentais e não governamentais para uma gestão transparente e para que o governo cumpra com a obrigação de prestar contas aos públicos interessados.

Primeiramente, buscou-se verificar se a gestão pública local dispõe de um setor de comunicação e de tecnologias que auxiliem na comunicação e difusão de informações de interesse público, inclusive no cumprimento das obrigações legais. O que foi observado, a partir das entrevistas e análise do site, é a ausência de canais de comunicação.

Os secretários entrevistados relataram que as informações financeiras das secretarias fazem parte do orçamento e da execução orçamentária, e essas informações são geradas automaticamente por um sistema e que, por determinação legal, são disponibilizados no site da prefeitura e no portal da transparência. Porém ressaltaram que não possuem acesso a essas informações, cuja publicização é gerenciada pela controladoria. 
As informações referentes às atividades das secretarias também não são publicadas diretamente por estas, pois existe um funcionário da prefeitura responsável por divulgar as ações de todas as secretarias no site da prefeitura. Ocorre que, por ser apenas um funcionário, as informações das secretarias disponibilizadas no site da prefeitura não são completas e atualizadas.

Dessa forma, percebe-se que os secretários não dispõem de condições para uma comunicação eficiente. Eles encontram problemas para levar ao público interessado as informações da sua secretaria. Também não se nota que esta seja uma 'preocupação', talvez pela falta de estrutura das secretarias, uma vez que estas, segundo os entrevistados, estão sobrecarregadas com as atividades rotineiras.

\section{CONSIDERAÇÕES FINAIS}

Levando em conta o objetivo deste artigo de compreender como a participação social se configura em termos práticos, nos arranjos de governança instituídos nos governos locais, especificamente em Viçosa, MG, não é possível dizer que existe uma governança participativa instituída nesse município.

O governo local apresenta tendência de manter modelos burocráticos e hierarquizados de governança pouco permeável a outros atores nos seus processos políticos e administrativos.

A gestão pública local não avança com as possibilidades de autonomia oriundas do processo de descentralização, nem em termos práticos, com a aproximação do cidadão para facilitar a resolução de conflitos, para gerar confiança, confiabilidade e respeito, para redução de pressão política e aumentar a legitimidade, nem em termos técnicos, com a instituição de mecanismos de transparência e possibilidades de responsabilização e combate a corrupção.

Dentre os desafios apresentados pelo governo local para a instituição de um modelo de governança participativa, destaca-se a sua relação de dependência com o governo central e o estadual para definições políticas. Embora se notem dificuldades do município, principalmente com a falta de autonomia financeira, que deixa os gestores municipais com pouca margem para atender as demandas da comunidade e formular políticas públicas adequadas à realidade local, isso contribui para inibir formas de governos mais participativas, parece que a principal questão é a falta vontade política para se instituir um modelo de governança participativa.

Pode-se observar que a falta de vontade política é também motivada por uma percepção por parte dos gestores de que a sociedade se encontra fragilizada para se apropriar do poder e utilizar dos espaços deliberativos de maneira efetiva. Talvez por esse fato, ainda que os gestores sinalizem preocupações pela garantia da eficiência, isto se dá numa proposta de administração fechada, com a cidadania marginalizada.

Conclui-se que o governo local mantém-se com a exclusividade para discutir e colocar em prática os projetos políticos e que, embora sejam sinalizados problemas de falta de confiança da sociedade em relação ao poder público, a governança participativa até o momento não foi pensada como alternativa para enfrentar os desafios, para estabelecer mecanismos de cooperação e restabelecer a confiança no setor público. 


\section{REFERÊNCIAS}

ARAÚJO, Cintia Rejane Moller. A participação societal na concepção das políticas públicas de turismo no Brasil: o caso do Conselho Municipal de Turismo de São Paulo no período de 1991 a 2006. 2007. Tese (Doutorado em Administração Pública) - EAESP, Fundação Getúlio Vargas (FGV), São Paulo, 2007.

AVRITZER, Leonardo. Instituições participativas e desenho institucional: algumas considerações sobre a variação da participação no Brasil democrático. Opinião Pública, Campinas, SP, v. 14, n. 1, p. 43-64, jun. 2008. BARDIN, Laurence. Análise de conteúdo. Lisboa: Edições 70, 1997.

BECK, Ivan. Reflexões sobre Estratégias de Governança Local. Revista Eletrônica Gestão e Sociedade, Belo Horizonte, v. 3, n. 5, p. 23-47, jan./jun. 2009.

BEVIR, Mark. Governance as theory, practice and dilema. In: BEVIR, M. (Ed.). The sage handbook of governance. Thousand Oaks, CA: Sage Publications, 2011.

Governança democrática: uma genealogia. Revista Sociologia Política, Curitiba, v. 19, n. 39, p. 103-14, jun. 2011.

BRASIL. Constituição da República Federativa do Brasil: 1988. 13. ed. Brasília: Câmara dos Deputados, Coordenação de Publicações, 2000.

BRUGUÉ, Quim. Recuperar la política desde la deliberación. Revista Internacional de Organizaciones, Tarragona, Espanha, n. 7, p. 157-74, dez. 2011.

CARNEIRO, Carla Bronzo. Conselhos de Políticas Públicas: desafios para sua institucionalização. Revista de Administração Pública - RAP, Rio de Janeiro, n. 36, v. 2, p. 277-92, mar./abr. 2002.

CARVALHO, Antônio Ivo de. Conselhos de Saúde no Brasil: participação cidadã e controle social. Rio de Janeiro: Ibam/Fasae, 1995.

CASTELLS, Manuel. Para o Estado-Rede: globalização econômica e instituições políticas na era da informação. In: CARLOS BRESSER, Luiz Carlos; WILHEIM, Jorge; SOLA, Lourdes (Org.). Sociedade e Estado em transformação. São Paulo: Editora Unesp, 2001.

COELHO, Vera Schattan P.; NOBRE, Marcos. Participação e deliberação: teoria democrática e experiências institucionais no Brasil contemporâneo. São Paulo: Ed. 34, 2004. 368p.

DALLABRIDA, Valdir R.; BECKER, Dinizar F. Governança territorial. Desenvolvimento em Questão, ljuí, RS, ano 1, n. 2, p. 73-97, jul./dez. 2003.

DINIZ, Eli. Crise, reforma do Estado e governabilidade. Rio de Janeiro: Fundação Getúlio Vargas, 1999.

Governabilidade, governance e reforma do Estado: considerações sobre o novo paradigma.

Revista do Setor Público, Brasília, DF, ano 47, v. 120, n. 2, p. 5-21, maio/ago. 1996.

FLICK, Uwe. Introdução à pesquisa qualitativa. 3. ed. Porto Alegre, RS: Artmed, 2009.

FREY, Klaus. Governança urbana e participação pública. RAC - Eletrônica, v. 1, n. 1, p. 136-50, jan./abr. 2007.

INSTITUTO BRASILEIRO DE GEOGRAFIA E ESTATÍ́STICA (IBGE). Pesquisas de Informações Básicas Municipais - Perfil dos Municípios Brasileiros 2016. Rio de Janeiro, 2016.

KEARNS, Ade. Active citizenship and local governance: political and geographical dimensions. Political Geography, v. 14, n. 2, p. 155-75, fev. 1995.

KISSLER, Leo; HEIDEMAN, Francisco G. Governança pública: novo modelo regulatório para as relações entre o Estado, mercado e sociedade? Revista de Administração Pública, Rio de Janeiro, v. 40, n. 3, p. 479-99, maio/jun. 2006.

LA FUENTE, José Manuel Ruano de. Contra la participación: discurso y realidad de las experiencias de participación ciudadana. Política y Sociedad, Madri, v. 47, n. 3, p. 93-108, 2010. 
MARTINS, Simone; CKAGNAZAROFF, Ivan Beck; LAGE, Mariana. Luísa da Costa. Análise dos Conselhos Gestores de Políticas Públicas à luz dos Relatórios de Fiscalização Controladoria Geral da União. APGS, Viçosa, MG, v. 4, n. 2, p. 221-45, abr./jun. 2012.

MARTINS, Simone. O exercício da democracia em Conselhos de Políticas Públicas. 2015. 373p. Tese (Doutorado em Administração)- Universidade Federal de Minas Gerais (UFMG), Belo Horizonte, 2015.

MAYNTZ, Renate. Nuevos desafíos de la teoría de 'governance'. Instituciones y Desarrollo, n. 7, p. 35-52, 2000. Disponível em: <http://www.iigov/revista/revista7/docs/mayntz.htm>.

MILANI, Carlos R. S. O princípio da participação social na gestão de políticas públicas locais: uma análise de exeriências latino-americanas e européias. Revista de Administração Pública - RAP, Rio de Janeiro, v. 42, n. 3, p. 551-79, maio/jun. 2008.

NESHKOVA, Milena I. Does agency autonomy fosters public participation? Public Administration Review, v. 74, n. 1, p. 64-74, jan./fev. 2014.

OLIVEIRA, Vírgílio C. S. de. Sociedade, Estado e Administração Pública: análise da configuração institucional dos Conselhos Gestores do Município de Lavras - MG. 2009. 303f. Tese (Doutorado em Administração) - Universidade Federal de Lavras (UFLA), Lavras, MG, 2009.

OFFE, Claus. Governance: na 'empty signifier'? Constellations, Oxford, v. 16, n. 4, p. 550-62, dez. 2009

PETERS, Guy. Governanza y Burocracia Pública: ¿nuevas formas de democracia e nuevas formas de control? Foro Internacional, Distrito Federal, México, v. XLV, n. 4, p. 585-98, out./dez. 2005.

PIRES, Roberto R. C. (Org.). Efetividade das instituições participativas no Brasil: estratégias de avaliação. Brasília: IPEA, 2011.

PIRES, Roberto; GOMIDE, Alexandre. Variações setoriais em arranjos de implementação de programas federais. Revista do Serviço Público, Brasília, v. 66, n. 2, p. 195-226, abr./jun. 2015.

RUEDIGER, Marco Aurélio. Governança democrática na era da informação. Revista de Administração Pública-RAP, Rio de Janeiro, v. 37, n. 6, p. 1257-80, nov./dez. 2003.

SABEL, Charles. Beyond principal-agent governance: experimentalist organizations, learning and accountability. In: ENGELEN, E.; HO, M. S. D. (Ed.). De Staat van de Democratie: democratie voorbij de staat. Amsterdam: Amsterdam University Press, 2004. p. 173-195.

SAMPAIO, Sergio B. A.; FARAH, Marta F. O olhar governamental sobre os Conselhos de Políticas Públicas: o caso do Conselho Municipal de Saúde de São Paulo no período de 2001 a 2004. In: ENAPG 2006 ENCONTRO DE ADMINISTRAÇÃO PÚBLICA E GOVERNANÇA. Anais... São Paulo, 2006.

SCHNEIDER, Volker. Redes de políticas públicas e a condução de sociedade complexas. CIVITAS - Revista de Ciências Sociais, Porto Alegre, RS, v. 5, n. 1, p. 29-58, jan./jun. 2005.

SPEER, Johanna. Participatory Governance Reform: a good strategy for increasing government responsiveness and improving public services? World Development, v. 40, n. 12, p. 2379-98, dez. 2012.

SUBIRATS, Joan. Nuevis mecanismos participativos y democracia: promesas y amenazas. In: FONT, J. (Ed.). Ciudadanos y decisions públicas. Barcelona: Ariel, 2001. p .33-42.

TELLES, Vera da S. Sociedade civil e a construção de espaços públicos. In: DAGNINO, E. (Org.). Anos 90: política e sociedade no Brasil. São Paulo: Brasiliense, 1994. p. 91-102.

VIEIRA, Marcelo Milano Falcão; ZOUAINS, Deborah Moraes. Pesquisa qualitativa em Administração: teoria e prática. Rio de Janeiro: FGV, 2005 


\section{Sobre os autores:}

Tainá Rodrigues Gomide Souza Pinto: Doutora em Administração pela Universidade Federal de Minas Gerais, Mestre em Administração pela Universidade Federal de Viçosa, Graduada em Direito pela Escola de Estudos Superiores de Viçosa e em Ciências Contábeis pela Universidade Federal de Viçosa. Professora do Departamento de Administração e Contabilidade da Universidade Federal de Viçosa (UFV), com atuação na área de administração, contabilidade e finanças públicas. E-mail: tainagomide@yahoo.com.br

Simone Martins: Doutora em Administração pela Universidade Federal de Minas Gerais, Mestre em Administração pela Universidade Federal de Viçosa, Graduada em Ciências Contábeis pela Universidade Federal de Minas Gerais. Professora do Departamento de Administração e Contabilidade da Universidade Federal de Viçosa (UFV). E-mail: simone.m@ufv.br

Danielle Silveira Leonel: Mestranda em Administração e graduada em Ciências Contábeis pela Universidade Federal de Viçosa (UFV). E-mail: leonel.danielle@gmail.com

Ivan Beck Ckagnazaroff: Doutor pelo Doctoral Programme Aston Business School - Aston University, mestre em Administração pela Universidade Federal de Minas Gerais, Graduado em Economia pela Pontifícia Universidade Católica de Minas Gerais. Professor dos cursos de graduação e de pós-graduação em Administração da Faculdade de Administração, Contabilidade e Econômica (CEPEAD) da Universidade Federal de Minas Gerais (UFMG). E-mail: ivanbeck00@ gmail.com 
